\title{
Hemiparetik Serebral Palsili Çocuklarda Sanal Gerçeklik Uygulamasının Kaba Motor Becerileri Üzerine Etkisi
}

\author{
Orkun Tahir Aran ${ }^{1}$, Sedef Şahin ${ }^{1}$, Barkın Köse ${ }^{2}$, Meral Huri ${ }^{3}$ \\ ${ }^{1}$ Hacettepe Üniversitesi Sağllk Bilimleri Fakültesi Ergoterapi Bölümü, Ankara \\ ${ }^{2}$ Hacettepe Üniversitesi Sağglı Bilimleri Fakültesi Ergoterapi Bölümü, Ankara \\ ${ }^{3}$ Hacettepe Üniversitesi Sağlık Bilimleri Fakültesi Ergoterapi Bölümü, Ankara
}

\begin{abstract}
Özet
Amaç: Sanal gerçeklik (SG) uygulamasının hemiparetik serebral palsili (HSP) çocukların kaba motor beceri düzeyi üzerine etkisini incelemek amacıyla planlandı.

Gereç ve Yöntem: Yaş ortalaması 10,4 \pm 2,92 yıl olan HSP’li çocuk (12 erkek-8 kız) çalışmaya dâhil edildi. Bilgisayar yazılımı için özel olarak programlanmış SG oyunları, haftada bir kez 30 dakika süreyle 8 hafta boyunca çocuklara uygulandı. Kaba motor beceri düzeyleri Bruininks - Oseretsky Motor Yeterlilik Testi Kısa Formu'nun (BOMYT-KF) 1-4 alt testleri ile müdahale öncesi, 4. ve 8. Haftalarda olmak üzere 3 kez tekrarlandı. Müdahalenin etkileri tekrarlanan ölçümler ANOVA yöntemi ile analiz edildi.

Bulgular: Çocukların 11'inin sağ ve 9'ununda sol HSP olduğu bulundu. Kaba motor beceri düzeyleri müdahale öncesi 7,60 $\pm 3,16$, müdahalenin 4. Haftasında 10,75 $\pm 2,61$, müdahale sonrası (8. haftada) $12,65 \pm 2,47$ olarak bulundu. BOMYT-KF’nun tüm alt testlerindeki artış, istatistiksel olarak anlamlı bulundu (p<0.05). 4. ve 8. Hafta ölçümleri arası ölçümlerde denge ve kuvvet alt bölümlerinde istatistiksel olarak anlamlı fark bulundu $(p<0.05)$.

Sonuç: HSP'li çocuklarda en az dört haftalık SG müdahalesi ile tedavi programlarının geliştirilmesinin, koşma, denge, bilateral koordinasyon ve kuvvet gibi kaba motor beceri düzeylerini artırabilir. HSP çocuklara yapılan rehabilitasyon uygulamalarında SG uygulamalarının daha yaygın olarak kullanılması ile çocukların motor becerilerinde daha fazla kazanım sağlayacağını düşünmekteyiz.
\end{abstract}

Anahtar kelimler: Serebral Palsi, İş Uğraşı Terapisi, Sanal Gerçeklik, Motor Beceri

Sorumlu Yazar: Orkun Tahir ARAN, Hacettepe Üniversitesi, Sağlık Bilimleri Fakültesi Ergoterapi Bölümü, Hacettepe Üniversitesi Sihhiye Kampüsü Sağlık Bilimleri Fakültesi Ergoterapi Bölümü 3. Kat, Ankara, Tel: 05075178972, e-mail: orkunaran@gmail.com

Gönderim Tarihi: 31 Ekim 2018

Kabul Tarihi: 16 Ocak 2019

Basım Tarihi: 25 Ocak 2019 
Original Research,

Effects of Virtual Reality on Gross Motor Skills

\title{
Effects of Virtual Reality Interventions on Gross Motor Function in Hemi-paretic Cerebral Palsy
}

\author{
Orkun Tahir Aran ${ }^{1}$, Sedef Şahin ${ }^{1}$, Barkın Köse ${ }^{2}$, Meral Huri $^{3}$ \\ ${ }^{1}$ Hacettepe University, Faculty of Healh Sciences, Occupational Therapy \\ ${ }^{2}$ Hacettepe University, Faculty of Healh Sciences, Occupational Therapy \\ ${ }^{3}$ Hacettepe University, Faculty of Healh Sciences, Occupational Therapy
}

\begin{abstract}
Objectives: It was aimed to analyze effect of virtual reality (VR) games on gross motor function of children with hemi-paretic Cerebral Palsy (HCP).

Material and Methods: 20 children with HCP with mean age 10,4 2,92 (12 boys, 8 girls) years were included. Specially programmed virtual reality games for PC SDK software were applied to the children twice a week for 30 minutes for 8 weeks. Gross motor function was evaluated with 1-4 subtests of the Bruininks - Oseretsky Motor Proficiency Test Short Form (BOMPT-SF). Intervention effects were analyzed with Repeated Measures ANOVA. Results: 11 of the children were right whereas 9 were left HCP. BOMPT-SF scores were 7,60 $\pm 3,16$ at preintervention, 10,75 $\pm 2,61$ at 4 th week, 12,65 $\pm 2,47$ at 8 th week. Significant increases were found for all subtests of BOMPT-SF $(\mathrm{p}<0.05)$. Significant statistical difference were found between strenght and balance subtests $(\mathrm{p}<0.05)$.

Conclusion: The development of treatment programs with at least four weeks SG intervention in children with HSP may increase the level of gross motor skills like running, balance, bilateral coordination and strength. We think that the more common use of SG applications in rehabilitation practices for HSP will provide more gain in motor skills.
\end{abstract}

Keywords: Cerebral Palsy, Occupational Therapy, Virtual Reality, Motor Skill

Corresponding Author: Orkun Tahir ARAN, Hacettepe University Faculty of Health Sciences Occupational Therapy, Adress: Hacettepe University Faculty of Health Sciences Occupational Therapy, Sihhiye, Ankara. Phone: 05075178972 email: orkunaran@gmail.com

Date of Submission: $31^{\text {st }}$ of October, 2018

Date of Acceptance: $16^{\text {th }}$ of January, 2019

Pub. Date: $25^{\text {th }}$ of January, 2019 


\section{Giriş}

Serebral Palsi (SP) gelişmekte olan beyinde meydana gelen, bebeklik çağından itibaren ortaya kalıcı olarak çıkan duyu, algı, motor ve kognitif beceri bozukluğu ile karakterize, ilerleyici olmayan bozukluklarla ilişkilendirilen çocukluk çağı nörolojik hastalığıdır (Anttila, Autti-Rämö, Suoranta ve diğ., 2008; Erdoğanoğlu ve Günel, 2010).

Dünyada görülme sıklığı her 1000 canlı doğumdan 1,5- 3 arasında, Türkiye' de ise 1000 canlı doğumda 4,4 olduğu belirtilmektedir (Oskoui, Coutinho, Dykeman ve diğ., 2013; Serdaroğlu, Cansu, Özkan ve diğ., 2006). Farklı tutulum seviyeleri ile seyreden çocukluk çağı nörolojik hastalığı olan SP'nin en yaygın tutulum gösterdiği tipinin hemiparetik tip (aynı taraf alt ve üst ekstremite etkilenimi) olduğu Galli ve ark. tarafından gösterilmiştir (Galli, Cimolin, Rigoldi ve di.̆., 2010).

En yaygın çocukluk çağı motor beceri yetersizliğine neden olarak kabul edilen SP, çocuklarda düzensiz kas tonusu, postüral kontrol yetersizlikleri, kas zayıflıkları ve denge bozukluklarına neden olabilmektedir (Mayston, 2002). Bu bozukluklar nedeniyle çocukların özellikle ayakta durma, yürüme, koşma, tek ayak üzerinde durma gibi kaba motor becerilerinde zorluk yaşadıkları sıkça vurgulanan bir konudur (Bailes, Gannotti, Bellows ve diğ., 2018; Wright, Lam, Mistry ve diğ., 2018).

Sanal gerçeklik (SG), bilgisayar yazılımlarının ve donanımlarının kombine edilmesi ile çeşitli boyutta ve duyusal uyaranlar oluşan sanal çevrede uygulanılan son yıllarda rehabilitasyon alanındaki çalışmalarda sıkça tercih edilen bir yöntemdir (Aran, Köse, Akel ve diğ., 2014; Aran, Şahin, Torpil ve diğ., 2017; Rose, Nam, ve Chen, 2018; Zhang, 2012). SG üç boyutlu olarak, katılımcıların interaktif katılım gösterdikleri, zevk alarak eğlenceli bir şekilde uygulanan bir tedavi yöntemidir (Steuer, 1992). Çocuklara yönelik rehabilitasyon uygulamalarında son yıllarda artan ilgiye sahip olan SG, gerçek ortamda yapılan uygulamalara oranla daha başarılı bir motivasyon sağlandığı gösterilmiştir (Bryanton, Bosse, Brien ve diğ., 2006; Holden ve Fletcher, 2005). SG uygulamalarında çocuğun görsel geri bildirim almasının yanı sıra, aktif katılım ve artırılmış motivasyon ile nöro-rehabilitasyonda motor öğrenmeyi desteklediği de gösterilmiştir (Loureiro, Amirabdollahian, Coote ve diğ., 2001). SG uygulamalarında, motor eğitimin farklı yöntemlerinin kullanımı, farklı geri bildirim yollarının alınması ve uygulama seans sıklığının, SP’li çocukların motor performansında değişikliğe sebep olabileceği vurgulanan diğer bir husustur (Bryanton ve diğ., 2006; Riener ve Harders, 2012). 
Son yıllarda SG uygulamasının yapıldığg çalışmalarda bu yöntemin, rehabilitasyonda önemli bir role sahip olduğu ve rehabilitasyonda kullanımını içeren farklı çalışmalara ihtiyaç olduğu belirtilmiştir (Riva, Bolzoni, Carella ve diğ., 1997). Özellikle, literatürde SG'in kaba motor beceriler üzerine direk etkisini ölçen bir çalışmaya rastlanamamıştır. $\mathrm{Bu}$ ihtiyaçlar 1şığında planladığımız çalışmanın amacı; SG uygulamasının hemiparetik serebral palsili (HSP) çocukların kaba motor beceri düzeyi üzerine etkisini araştırmaktır.

\section{Gereç ve Yöntem}

Çalışmamıza HSP tanısı ile rehabilitasyona devam eden 20 çocuk dâhil edildi. Araştırma, Helsinki Deklarasyonu'na uygun olarak dâhil edilme kriterlerini sağlayan ve çalışmaya gönüllü olarak katılmayı kabul edenlerde, bilgilendirilmiş onam formu imzalatılarak yapild1.

Çocuklar için çalışmaya dâhil edilme kriterleri; (1) HSP tanısı almış olmak; (2) GMFCS'ye göre 1-3 seviyeleri arasında olmaktı. Dâhil edilmeme kriterleri ise (1) Son 6 ay içerisinde botulinum toksin enjeksiyonu olmak, (2) Çalışmanın yürütüldüğü dönemde cerrahi operasyona dahil olma (gevşetme cerrahisi vb.) ve çalışmaya katılmak istememek olarak belirlendi.

Çalışmaya dâhil edilen tüm çocukların kaba motor performans düzeylerini değerlendirmek için Bruininks - Oseretsky Motor Yeterlilik Testi Kısa Formu (BOMYT-KF) uyguland1.

\section{Veri Toplama Araçları}

Sosyo-demografik Bilgi Formu: Araştırmacılar tarafından hazırlanmış olan yarı yapılandırılmış görüşme formudur. Formda çocukların yaş, cinsiyet, etkilenim gösteren ekstremite ve dominant ekstremite hakkında bilgilerin yer aldığı bölümler bulunmaktadır.

Bruininks - Oseretsky Motor Yeterlilik Test- Kısa Formu (BOMYT-KF): Çocukların kaba motor performansını değerlendirmek amacıyla BOMYT-KF kullanıldı. Bu test bataryası 4,5-16,5 yaşları arasındaki çocukların kaba ve ince motor fonksiyonlarını değerlendirmek için kullanılmaktadır (Deitz 2007). Testin tamamı 45-60 dk' da tamamlanabilir iken, bizim kullandığımız kısmı olan kaba motor performans kısmı 15-20 dk içinde tamamlanabilmektedir.

BOMYT-KF'nun kaba motor perfomansı değerlendiren 'Koşma Hızı ve Çeviklik', 'Denge', 'Bilateral Koordinasyon' ve 'Kuvvet' alt testleri (ilk 4 Madde) kullanıldı. 
- Koşma Hızı ve Çeviklik: Çocuk, başlangıç çizgisinden itibaren 15 yard'lık $(13,7 \mathrm{~m})$ mesafeyi mümkün olan en yüksek hızda koşmaya başlar ve tekrar başlangıç çizgisine döndügünde kronometre durdurulur.

- Denge: Spesifik denge becerileri iki alt test ile değerlendirildi. Alt test 1: Denge Tahtasında Dominant Ayak Üzerinde Durma (Gözler Açık), tek ayak üzerinde ve ellerini beli üzerine yerleştirerek $3 \mathrm{~m}$ uzakta yer alan göz hizasındaki hedefe bakarak 10 saniye dengede kalmaya çalışır ve süre tutulur. Tutulan süreye göre puan çizelgesinde 0-4 puan arasında skorlanır. Alt test 2: Denge Tahtasında İleri Doğru Topuk-Parmak Yürüyüşü yaparak öne doğru ardışık 6 adım atmaya çalışır ve atabildiği adım sayısı toplanır. Attığı adım sayısına göre puan çizelgesinde 0-4 puan arasında skorlanır.

- Bilateral Koordinasyon: İki alt test ile değerlendirildi. Alt test 1; Parmaklarla daire çizerken, ayakları sırayla indirip kaldırması istenir ve doğru yapıp yapmadığına bakılarak 0 ya da 1 puan verilir. Alt test 2; Çift Ayak ile Siçrarken Elleri Birbirine Vurması istenir (alkış yapma) ve sayısı not edilir. Ardışık olarak zıplama sayısına gör puan çizelgesinde 0- 4 puan arasında skorlanır.

- Kuvvet: Ayakuçlarını başlangıç çizgisine yerleştirilerek, ileriye doğru olabildiğince uzun atlama yaparak zıplaması istenir ve mesafe ölçülür.

BOMYT-KF’nun çeşitli dillerde ve farklı tanı gruplarında geçerlilik ve güvenilirliği olduğu gösterilmiştir (Lucas, Latimer, Doney ve diğ., 2013; Wuang ve Su, 2009). Türkçe dilinde geçerlilik ve güvenilirliği de Köse ve Mülazımoğlu Ballı tarafından yapılmıştır (Köse, 2018; Mülazımoğlu Ballı, 2006).

\section{Sanal Gerçeklik Uygulamaları}

Çalışmamızda sanal gerçeklik ara yüzü olarak Microsoft Kinect for PC kullanıldı. Microsoft Kinect; derinlik sensörü, renkli kamera ve 4 mikro sensor ile kişinin vücudunu algılayıp 3 boyutlu hareket yakalama sistemi sunmaktadır. Üç boyutlu hareket yakalama sistemi ile bireyler vücut hareketleri ile Kinect'e özel uygulanmış oyunları kontrol edebilmektedir.

Çalışmamızdaki müdahale uygulamalarında; Star3dme firmasının Kinect for PC için hazırladığı oyunlardan Jet Run, Boxing Trainer ve Brick Breaker kullanıldı. Jet Run yapay zekaya karşı yapılan yarış oyunudur. Oyuncu, oyun içindeki avatarı alt ekstremiteleri sabitken, gövde lateral fleksiyonu aracılığı ile kontrol eder. Boxing Trainer oyununda oyuncu 6 farklı yükseklik seviyesinde bulunan hedeflere yeterli kuvvetle yumruk atmayı içeren bir boks oyunudur. Brick Breaker ise oyuncunun tenis topu aracılığı ile karşısında bulunan duvarları vurup puan kazanmaya çalışılan bir oyundur. Bu SG uygulamaları HSP'li bir çocuğun gövde 
dengesi, ekstremite kontrolü, ağırlık aktarma gibi kaba motor becerileri içermesinden dolayı, çalışmamızda kullanıldı.

Uygulamalar 8 hafta boyunca, haftada 1 kez olmak üzere $30 \mathrm{dk}$ ' lık programlarla yapıldı. Ayrıca bütün katılımcılar haftada 1 kez rutin olarak katıldıkları özel eğitim ve rehabilitasyon merkezlerindeki rehabilitasyonlarına devam ettiler. Oyunların hepsi bir seansta en az 1 kere kullanıldı. Uygulama alanının zemini yumuşak material ile kaplanmış durumda olması ile çocukların düşme riskine karşı ortaya çıkabilecek problemleri ortadan kaldırmak hedeflendi ve yine düşme riskini artırmamak için çocukların yorulduğunda dinlenmesini sağlayacak şekilde 5 dakikayı geçmemek koşulu ile mola vermelerine izin verildi.

\section{İstatistiksel Analiz}

Verilerin analizinde 'Statistical Package for the Social Sciences 23.0 for Windows (SPSS)’ programı kullanıldı. İstatistiksel ölçüm sonucu belirlenen değişkenler ortalama \pm standart sapma şeklinde $(\mathrm{X} \pm \mathrm{SS}$ ) olarak ifade edilmiş, sayımla belirlenen değişkenler için yüzde (\%) değeri hesaplanmıştır. Müdahalenin etkinliğinin incelenmesi için uygulama öncesi, uygulama ara ölçümü (4.hafta) ve uygulama sonrası (8. Hafta) elde edilen veriler General Lineer Model Tekrarlanan Ölçümler Anova testi ile değerlendirildi ve p değeri için Bonferonni düzeltmesi uygulandı. Çalışmamızda istatistiksel anlamlılık düzeyi \%5 olarak kabul edildi.

\section{Bulgular}

Çalışmamıza HSP tanısı ile takip edilen yaş ortalaması 10,4 $\pm 2,92$ yıl olan 20 çocuk (12 erkek; 8 kı) dahil edildi. Çocukların 11'inin sağ ve 9'ununda sol HSP olduğu bulundu. Kaba motor beceri düzeyleri müdahale öncesi 7,60 $\pm 3,16$, müdahalenin 4 . Haftasında 10,75 \pm 2,61, müdahale sonrası ( 8 . haftada) 12,65 $\pm 2,47$ olarak bulundu (Tablo 1). Müdahale uygulamaları sonucunda HSP'li çocukların hem 4. hafta hem de 8. hafta sonrasında kaba motor becerilerinde anlamlı fark bulundu $(\mathrm{p}<0,05)$. BOMYT-KF alt testlerinden "Koşma Hızı ve Çeviklik" bölümünde 4.haftada; "Denge" alt parametresinde hem 4. haftada hem de 8. haftada; "Bilateral Koordinasyon" alt parametresinde 4. haftada ve "Kuvvet" alt parametresinde ise hem 4.hafta hem de 8.haftada yapılan değerlendirmelerde istatistiksel olarak olumlu yönde gelişmeler olduğu bulundu $(\mathrm{p}<0,05)$ (Tablo 2). 
Tablo 1. Bruininks - Oseretsky Motor Yeterlilik Test- Kısa Formu sonuçları

\begin{tabular}{|c|c|c|c|c|}
\hline $\begin{array}{l}\text { BOTMY-KS alt } \\
\text { parametreleri }\end{array}$ & $\begin{array}{l}\text { Müdahale } \\
\text { Öncesi }\end{array}$ & $\begin{array}{l}\text { Müdahalenin } \\
\text { 4. haftası }\end{array}$ & $\begin{array}{l}\text { Müdahale } \\
\text { sonrası }\end{array}$ & $\mathbf{p}$ \\
\hline $\begin{array}{l}\text { Koşma Hizı ve } \\
\text { Çeviklik }\end{array}$ & $2,55 \pm 2,32$ & $3,4 \pm 1,78$ & $3,6 \pm 1,53$ & $0,001 *$ \\
\hline Denge & $3,3 \pm 1,80$ & $4,75 \pm 1,20$ & $5,9 \pm 1,2$ & $0,001 *$ \\
\hline $\begin{array}{l}\text { Bilateral } \\
\text { Koordinasyon }\end{array}$ & $0,8 \pm 0,69$ & $1,2 \pm 0,76$ & $1,4 \pm 0,82$ & $0,001 *$ \\
\hline Kuvvet & $0,95 \pm 0,68$ & $1,4 \pm 0,59$ & $1,75 \pm 0,71$ & $0,001 *$ \\
\hline Toplam & $7,60 \pm 3,16$ & $10,75 \pm 2,61$ & $12,65 \pm 2,47$ & $0,001 *$ \\
\hline
\end{tabular}

BOTMY-KS: Bruininks - Oseretsky Motor Yeterlilik Test- Kısa Formu, ${ }^{*} \mathrm{p}<0,05$

Tablo 2. Bruininks - Oseretsky Motor Yeterlilik Test- Kısa Formu Müdahale Değişimlerinin Karşılaştırılması

\begin{tabular}{llll}
\hline \multicolumn{1}{c}{$\begin{array}{c}\text { BOTMY-KS alt } \\
\text { parametreleri }\end{array}$} & $\begin{array}{l}\mathbf{1 - 2} \text { karşılaştırma } \\
\mathbf{p}\end{array}$ & $\begin{array}{l}\mathbf{1 - 3} \text { karşılaştırma } \\
\mathbf{p}\end{array}$ & $\begin{array}{l}\mathbf{2 - 3} \text { karşılaştırma } \\
\mathbf{p}\end{array}$ \\
\hline $\begin{array}{l}\text { Koşma Hızı ve } \\
\text { Çeviklik }\end{array}$ & $0,002^{*}$ & $0,001^{*}$ & 0,311 \\
$\begin{array}{l}\text { Denge } \\
\text { Bilateral }\end{array}$ & $0,0001^{*}$ & $0,0001^{*}$ & $0,0001^{*}$ \\
Koordinasyon & $0,006^{*}$ & $0,003^{*}$ & 0,09 \\
Kuvvet & & & \\
Toplam & $0,01^{*}$ & $0,001^{*}$ & $0,014^{*}$ \\
\hline
\end{tabular}

1: Müdahale öncesi değerlendirme, 2: Müdahalenin 4. Haftası değerlendirme, 3: Müdahale sonrası değerlendirme, $\mathrm{p}$ : Bonferroni düzeltmesi ile istatistiksel anlamlılık düzeyi, ${ }^{*} \mathrm{p}<0,05$

\section{Tartışma ve Sonuç}

Çalışmamızda HSP'li çocuklara uygulanan sanal gerçeklik müdahalesi sonrası kaba motor beceri düzeylerinin arttığı bulundu. HSP tanısı ise takip edilen bir çocuğun motor becerilerinin artırılması için haftada 1 kez yapılan 30 dakikalık sanal gerçeklik yaklaşımının 4 hafta süre ile uygulanmasının çocuklarda değişim sağladığı ve aynı müdahalenin 8 hafta boyunca uygulanması sonucunda ise gelişimin devam ettiği çalışmamızda gösterildi.

SP'li çocuklarda kaba motor becerilerini geliştirmek için aktif video oyunlarının kullanımının kanıtı, Nintendo Wii ve WiiFit için, oyunla etkileşimin elle kontrol edilen bir kumanda veya bir kuvvet platformu üzerinden yapıldığı sistemler için gösterilmiştir (Jelsma, Pronk, Ferguson ve diğ., 2013; Levac, McCormick, Levin ve diğ., 2018). Bütün vücudun hareketini içeren Microsoft'un Xbox360 Kinect hareket yakalama sensör oyunlarının 
rehabilitasyon alanındaki kullanımı ve literatürdeki yeri her geçen gün artmaktadır (Levac ve diğ., 2018). SP'li çocuklarda yapılan çalışmalardada, üst ekstremite fonksiyonu, yürüme dayanıklılığı ve koşma gibi kaba motor becerilerde gelişme olduğunu gösterilmiştir (Chang, Han, ve Tsai, 2013; Cho, Hwang, Hwang ve diğ., 2016; Rathinam, Mohan, Peirson ve diğ., 2018). Çalışmamızda HSP'li çocuklara 8 hafta boyunca uygulanan sanal gerçeklik yaklaşımlarının, 4. haftasında kaba motor becerilerde gelişme olduğu, 8. haftada da elde edilen gelişimin devam ettiği görüldü. Bu sonuçlar 1şı̆̆ında çalışmamız literatürdeki sonuçları destekler niteliktedir.

Levac ve arkadaşları 5 SP'li çocuğa uyguladıkları 6 haftalık sanal gerçeklik uygulamalarının sonucunda kaba motor fonksiyon seviyesinde olumlu yönde gelişme olduğunu belirtmişlerdir (Levac ve diğ., 2018. Gagliardi ve arkadaşları ise sanal gerçeklik uygulamalarının 6 metre yürüme testi, yürüme enduransı ve yürüme hızı üzerine olumlu değişimler ortaya çıkardığını belirtmişlerdir (Gagliardi, Turconi, Biffi ve diğ., 2018). Çalışmamızda HSP'li çocukların “Koşma Hızı ve Çeviklik” becerilerinde anlamlı artış bulundu. Rehabilitasyon sırasında kullanılan oyunların çocukların ayakta durma, ayakta farklı pozisyonlarda ağırlık aktarma, diz fleksiyon-ekstansiyonu gibi becerileri kullanması nedeniyle çocukların gelişme gösterdiği düşünülmektedir. Bu sonuç doğrultusunda SP'li çocukların koşma hızı ve çeviklik gibi kaba motor becerilerinde kazanım sağlanması için, SG uygulamasının rehabilitasyon yaklaşımları içerisinde kullanımını önermekteyiz.

Literatürde SG uygulamalarının denge üstüne etkisini araştıran birçok çalışma olmakla birlikte, Wii, Wii-Fit, Playstation Eye-toy ve Kinect gibi uygulamaların SP'li çocukların denge becerilerini geliştirdiğini göstermiştir (Jelsma ve diğ., 2013; Rand, Kizony, ve Weiss, 2008; Sharan, Ajeesh, Rameshkumar ve diğ., 2012). Çalışmamızda yapılan SG uygulamasının da SP'li çocukların denge becerilerini geliştirdiği görüldü. Elde ettiğimiz bulgular 1şığında,en az 4 haftalık SG uygulaması ile HSP'li çocukların denge becerilerini olumlu yönde geliştirilebileceğini düşünmekteyiz. Klinik olarak daha fazla gelişimin gerektiği durumlarda ise terapistlerin 8 haftalık uygulamaları tercih etmesini çalışmanın sonuçları doğrultusunda önerilmektedir.

Çalışmamızda 4 haftalık SG uygulamasının bilateral motor koordinasyonu geliştirdiği ve bu gelişimin 8 haftalık programın sonuna kadar korunduğu; aynı uygulamaların alt ekstremite kuvvetini 4 haftada geliştirdiği ve 8 hafta boyunca da geliştirmeye devam ettiği bulundu. Çalışmamızda kullanılan oyunların içindeki görevlerin yapılabilmesi için çocuklarda üst ekstremite koordine hareketlerini ve alt ekstremite hareketlerinden kalça ve diz fleksiyonu- 
ekstansiyonunu içermesinin özellikle denge, bilateral motor koordinasyon ve kuvveti geliştirdiği düşünülmektedir. Literatürde SG uygulamalarının SP'li çocukların hem üst hem de alt ekstremite bilateral motor koordinasyonu ve kuvveti üzerine etkisini araştıran çalışmalara rastlanılmamıştır. Elde ettiğimiz bu bulgular, literatüre yeni bilgiler sunmakta ve bu bulgular 1şığında planlanacak yeni araştırmalara da yön vereceği düşünülmektedir.

HSP'li çocuklarda kaba motor beceri değerlendirilmesi sırasında motor beceriyi düzeyini etkileyebilecek olan spastisite ve alt ekstremite kas kuvvetinin incelenmemiş olmasının, örneklem büyüklüğü için ön analiz yapılmamasının çalışmamızın limitasyonu olduğunu düşünmekteyiz.

Sonuç olarak, HSP'li çocuklarda en az dört haftalık SG müdahalesi ile tedavi programlarının geliştirilmesinin, koşma, denge, bilateral koordinasyon ve kuvvet gibi kaba motor beceri düzeylerini artırabilir. HSP çocukların rehabilitasyon uygulamalarında SG uygulamalarının daha yaygın olarak kullanılması ile çocukların motor becerilerinde önemli kazanımlar sağlayacağını düşünmekteyiz.

\section{Finansal Destek}

Çalışma için herhangi bir finansal destek sağlanmamıştır.

\section{Çıkar Çatışması}

Yazarlar arasında herhangi bir çıkar çatışması yoktur 


\section{Kaynakça}

Anttila, H., Autti-Rämö, I., Suoranta, J., Mäkelä, M., ve Malmivaara, A. (2008). Effectiveness of physical therapy interventions for children with cerebral palsy: a systematic review. $B M C$ pediatrics, 8(1), 14.

Aran, O. T., Köse, B., Akel, B. S., ve Öksüz, Ç. (2014). Ataksili Bir Bireyde Sanal Gerçeklik Temelli Rehabilitasyon Uygulamasının Etkinliği-Olgu Raporu. Ergoterapi ve Rehabilitasyon Dergisi, 2(3), 159-164.

Aran, O. T., Şahin, S., Torpil, B., Demirok, T., ve Kayıhan, H. 1. (2017). Virtual Reality and Occupational Therapy Occupational Therapy-Occupation Focused Holistic Practice in Rehabilitation: InTech.

Bailes, A. F., Gannotti, M., Bellows, D. M., Shusterman, M., Lyman, J., ve Horn, S. D. (2018). Caregiver knowledge and preferences for gross motor function information in cerebral palsy. Developmental Medicine \& Child Neurology.

Bryanton, C., Bosse, J., Brien, M., Mclean, J., McCormick, A., ve Sveistrup, H. (2006). Feasibility, motivation, and selective motor control: virtual reality compared to conventional home exercise in children with cerebral palsy. Cyberpsychology \& behavior, 9(2), 123-128.

Chang, Y.-J., Han, W.-Y., ve Tsai, Y.-C. (2013). A Kinect-based upper limb rehabilitation system to assist people with cerebral palsy. Research in developmental disabilities, 34(11), 3654-3659.

Cho, C., Hwang, W., Hwang, S., ve Chung, Y. (2016). Treadmill training with virtual reality improves gait, balance, and muscle strength in children with cerebral palsy. The Tohoku journal of experimental medicine, 238(3), 213-218.

Erdoğanoğlu, Y., ve Günel, Y. (2010). Serebral paralizili çocukların motor ve fonksiyonel seviyeleri ile sağlıkla ilgili yaG̣am kaliteleri arasındaki iliG̣kinin incelenmesi. Toplum Hekimliği Bülteni, 26(3), 13-18.

Gagliardi, C., Turconi, A. C., Biffi, E., Maghini, C., Marelli, A., Cesareo, A., ve diğ. . (2018). Immersive virtual reality to improve walking abilities in cerebral palsy: a pilot study. Annals of biomedical engineering, 1-9.

Galli, M., Cimolin, V., Rigoldi, C., Tenore, N., ve Albertini, G. (2010). Gait patterns in hemiplegic children with cerebral palsy: comparison of right and left hemiplegia. Research in developmental disabilities, 31(6), 1340-1345.

Holden, S. H., ve Fletcher, P. D. (2005). The virtual value chain and e-government partnership: nonmonetary agreements in the IRS e-file program. International Journal of Public Administration, 28(7-8), 643-664.

Jelsma, J., Pronk, M., Ferguson, G., ve Jelsma-Smit, D. (2013). The effect of the Nintendo Wii Fit on balance control and gross motor function of children with spastic hemiplegic cerebral palsy. Developmental neurorehabilitation, 16(1), 27-37.

Köse, B. (2018). Bruininks-Oseretsky Motor Yeterlik Testi 2 Kısa Formunun Türkçe Uyarlaması ve Özgül Öğrenme Güçlüğü Olan Çocuklarda Geçerlilik ve Güvenilirliği.

Levac, D., McCormick, A., Levin, M. F., Brien, M., Mills, R., Miller, E., ve diğg. . (2018). Active video gaming for children with cerebral palsy: Does a clinic-based virtual reality component offer an additive benefit? A pilot study. Physical \& occupational therapy in pediatrics, 38(1), 74-87.

Loureiro, R., Amirabdollahian, F., Coote, S., Stokes, E., ve Harwin, W. (2001). Using haptics technology to deliver motivational therapies in stroke patients: Concepts and initial pilot studies. Paper presented at the Proceedings of EuroHaptics.

Lucas, B. R., Latimer, J., Doney, R., Ferreira, M. L., Adams, R., Hawkes, G., ve diğ. . (2013). The Bruininks-Oseretsky test of motor proficiency-short form is reliable in children living in remote Australian aboriginal communities. BMC pediatrics, 13(1), 135.

Mayston, M. (2002). 10 Physiotherapy Management In Cerebral Palsy: An Update On Treatment Approaches. Clinics in Developmental Medicine(161), 147-160.

Mülazımoğlu Ballı, Ö. (2006). Bruininks-Oseretsky Motor Yeterlik Testinin Geçerlik, Güvenirlik Çalışması Ve Beş-Altı Yaş Grubu Çocuklara Uygulanan Cimnastik Eğitim Programının Motor Gelişime Etkisinin İncelenmesi. Yayımlanmamış doktora tezi. Ankara: Ankara Üniversitesi. Fen Bilimleri Enstitüsü. 
Oskoui, M., Coutinho, F., Dykeman, J., Jetté, N., ve Pringsheim, T. (2013). An update on the prevalence of cerebral palsy: a systematic review and meta-analysis. Developmental Medicine \& Child Neurology, 55(6), 509-519.

Rand, D., Kizony, R., ve Weiss, P. T. L. (2008). The Sony PlayStation II EyeToy: low-cost virtual reality for use in rehabilitation. Journal of neurologic physical therapy, 32(4), 155-163.

Rathinam, C., Mohan, V., Peirson, J., Skinner, J., Nethaji, K. S., ve Kuhn, I. (2018). Effectiveness of virtual reality in the treatment of hand function in children with cerebral palsy: A systematic review. Journal of Hand Therapy.

Riener, R., ve Harders, M. (2012). Virtual reality for rehabilitation Virtual Reality in Medicine (pp. 161180): Springer.

Riva, G., Bolzoni, M., Carella, F., Galimberti, C., Griffin, M., Lewis, C., ve diğ. . (1997). Virtual reality environments for psycho-neuro-physiological assessment and rehabilitation. Studies in health technology and informatics, 39, 34-45.

Rose, T., Nam, C. S., ve Chen, K. B. (2018). Immersion of virtual reality for rehabilitation-Review. Applied ergonomics, 69, 153-161.

Serdaroğlu, A., Cansu, A., Özkan, S., ve Tezcan, S. (2006). Prevalence of cerebral palsy in Turkish children between the ages of 2 and 16 years. Developmental medicine and child neurology, 48(6), 413-416.

Sharan, D., Ajeesh, P., Rameshkumar, R., Mathankumar, M., Paulina, R. J., ve Manjula, M. (2012). Virtual reality based therapy for post operative rehabilitation of children with cerebral palsy. Work, 41(Supplement 1), 3612-3615.

Steuer, J. (1992). Defining virtual reality: Dimensions determining telepresence. Journal of communication, 42(4), 73-93.

Wright, F. V., Lam, C. Y., Mistry, B., ve Walker, J. (2018). Evaluation of the reliability of the Challenge when used to measure advanced motor skills of children with cerebral palsy. Physical \& occupational therapy in pediatrics, 38(4), 382-394.

Wuang, Y.-P., ve Su, C.-Y. (2009). Reliability and responsiveness of the Bruininks-Oseretsky Test of Motor Proficiency-in children with intellectual disability. Research in Developmental Disabilities, 30(5), 847-855.

Zhang, Z. (2012). Microsoft kinect sensor and its effect. IEEE multimedia, 19(2), 4-10. 